\title{
Anticoagulant Therapy in Japanese Patients With Mechanical Mitral Valves
}

\author{
Katsuhiko Matsuyama, MD; Masahiko Matsumoto, MD; \\ Takaaki Sugita, MD; Junichiro Nishizawa, MD; Kazunori Yoshida, MD; \\ Yoshiyuki Tokuda, MD; Takehiko Matsuo, MD
}

\begin{abstract}
There are no guidelines for the optimal therapeutic range of anticoagulant therapy in Japanese patients with mechanical heart valves. A total of 214 patients were followed retrospectively after mitral mechanical valve replacement (mean duration of follow-up, 4.8 years; total duration of follow-up, 1,027 patient-years). The target range of the international normalized ratio (INR) for oral anticoagulation was between 1.5 and 2.5. For all patients 10,416 measurements of the INR were obtained during the follow-up period and approximately $76 \%$ of the intensity measurements were within the target range. Thromboembolism occurred in 8 patients $(0.8$ per 100 patient-years) and major bleeding in 5 patients ( 0.5 per 100 patient-years). There was no correlation between the distribution of the INR and the occurrence of thromboembolic or bleeding complications. In the univariate analysis of the various risk factors, patients who had a tilting valve or did not receive antiplatelet therapy had an increased risk of thromboembolism. However, there were no risk factors with respect to bleeding complications. A target range of 1.5 to 2.5 INR appears to be the optimal range and is safe for thromboembolism or bleeding complications. Thromboembolism may be reduced by additional antiplatelet therapy, and a tilting valve needs more intense anticoagulation. (Circ J 2002; 66: 668-670)
\end{abstract}

Key Words: Anticoagulant intensity; Bleeding complications; Mechanical heart valves; Thromboembolism

$\mathbf{T}$ hromboembolic and hemorrhagic complications, which are the main causes of morbidity and mortality in patients with mechanical heart valves, have been reported to depend on the intensity of the anticoagulation regimen! The current recommendation for Asian patients is a low intensity of anticoagulation because they seem to be less vulnerable to thrombotic disease than Caucasians; ${ }^{2,3}$ however, there are no specific guidelines for the optimal anticoagulant therapeutic range in Japanese patients with mechanical heart valves.

The purpose of this study was to determine the incidence of thrombotic and bleeding complications associated with mitral valve prostheses in order to examine the correlation between the intensity of anticoagulation and the occurrence of these events, and to determine the risk factors for the complications.

\section{Methods}

Between January 1995 and January 2001, a total of 214 patients with mitral mechanical valves were followed retrospectively: 134 patients had undergone surgery before January 1995, and 80 patients from that date until January 2000. The follow-up ended if a patient died or moved to a different region; the mean duration of follow-up was 4.8 years and the total duration was 1,027 patient-years. Patient age was defined as the age at the time of surgery or at the beginning of the follow-up. Thromboembolic events in-

(Received January 18, 2002; revised manuscript received March 29, 2002; accepted April 3, 2002)

Department of Cardiovascular Surgery, Tenri Hospital, Tenri, Japan Mailing address: Katsuhiko Matsuyama, MD, Department of Cardiovascular Surgery, Tenri Hospital, 200 Mishima, Tenri 632-8552, Japan cluded cerebral infarction, peripheral embolism, and valve thrombosis. Cerebral infarction was defined as sudden temporary or permanent neurologic defect. Hemorrhagic episodes included fatal bleeding, intracranial bleeding or any bleeding requiring a blood transfusion and hospitalization. All events that occurred during an episode of endocarditis were excluded. The patients were monitored on average once per month. The target range of the international normalized ratio (INR) for oral anticoagulation was between 1.5 and 2.5 , and the INR at the time of an event was obtained from the hospital records. If the INR had not been determined or was unavailable, the last INR recorded was used. Some patients received warfarin concomitantly with antiplatelet agents such as $81 \mathrm{mg}$ of aspirin daily, 200 $\mathrm{mg}$ of dipyridamole daily, or $200 \mathrm{mg}$ of ticlopidine daily by physicians' preference.

The continuous variables were expressed as means $\pm \mathrm{SD}$, and were compared by Student's $t$ test. The qualitative variables were expressed as percentages, and were compared by the chi-squared test. A p value less than 0.05 was considered to be statistically significant.

\section{Results}

The baseline characteristics of the patients are listed in Table 1 . There were 13 deaths during the follow-up period (1.2 per 100 patient-years). Cerebral infarction occurred in 8 patients ( 0.8 per 100 patient-years) with a mean age of 59 years (range, 45-68): 1 patient died, but the others had only temporary or mild neurological dysfunction. There was not a case of either peripheral embolism or valve thrombosis during follow-up. Major bleeding occurred in 5 patients (chronic subdural hematoma in 1 patient, cerebellar bleeding in 1 , gastrointestinal bleeding in 3 ) ( 0.5 per 100 patient- 
Table 1 Baseline Characteristics and Incidence of Thromboembolic or Bleeding Complications

\begin{tabular}{lccc}
\hline \hline & Total & Thromboembolism & Bleeding \\
\hline No. of patients & 214 & 8 & 5 \\
Age (years) & $59 \pm 13$ & $59 \pm 3$ & $67 \pm 5$ \\
& $($ range $12-81)$ & (range $45-68)$ & (range 59-71) \\
Female sex & $99(46 \%)$ & 4 & 3 \\
Atrial fibrillation & $168(79 \%)$ & 6 & 5 \\
Left atrial dimension $(>60 \mathrm{~mm})$ & $74(35 \%)$ & 3 & 2 \\
Ejection fraction of LV $(<50 \%)$ & $51(24 \%)$ & 0 & 0 \\
Absence of antiplatelet therapy & $67(31 \%)$ & $5 *$ & 2 \\
Hyperlipidemia & $19(9 \%)$ & 3 & 0 \\
Diabetes mellitus & $33(15 \%)$ & 2 & 1 \\
Ischemic heart disease & $24(11 \%)$ & 2 & 0 \\
Dialyzed renal failure & $4(2 \%)$ & 0 & 0 \\
Tilting valve & $12(6 \%)$ & $3 * *$ & 1 \\
Björk-Shiley & 7 & 2 & 0 \\
Ominiscience & 5 & 1 & 1 \\
Concomitant AVR & $58(27 \%)$ & 1 & 0 \\
St Jude Medical & 27 & 1 & 1 \\
CarboMedics & 31 & 0 & 5 \\
Rheumatic etiology & $181(85 \%)$ & 8 & \\
\hline
\end{tabular}

${ }^{*} p=0.04, * * p<0.0001 . L V$, left ventricle; AVR, aortic valve replacement.

Table 2 Risk Factors for Thromboembolism Using Multivariate Analysis

\begin{tabular}{lccc}
\hline \hline Factors & $p$ value & Hazard ratio & $95 \%$ confidence interval \\
\hline Tilting valve & 0.002 & 17.7 & $2.9-107.3$ \\
Absence of antiplatelet therapy & 0.04 & 6.3 & $1.1-37.5$ \\
\hline
\end{tabular}

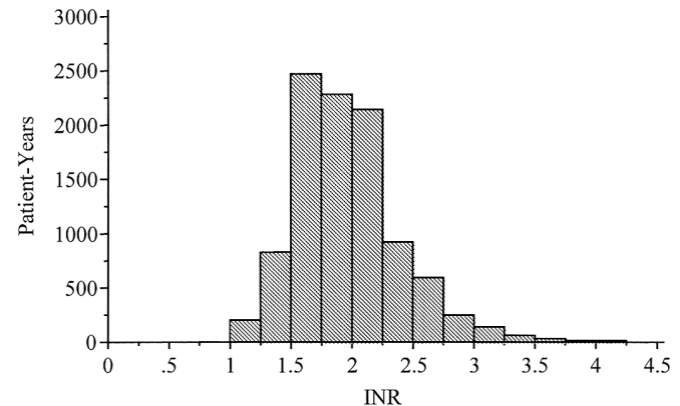

Fig 1. Distribution of patient-years in each INR unit. INR, international normalized ratio.

years) with a mean age of 67 years (range, 59-71); the patient with cerebellar bleeding died.

For all 214 patients, 10,416 measurements of prothrombin time were obtained during the follow-up period and the distribution of the patient-time over the INR categories is summarized in Fig 1: approximately $76 \%$ of the intensity measurements were within the target range, $10 \%$ were below the range, and $14 \%$ were above the upper range. Antiplatelet agents was administered with warfarin concomitantly in 147 patients: aspirin in 77 patients, dipyridamole in 31, ticlopidine in 29 . The INR at the time of an event was within the target range in $7(88 \%)$ of 8 patients with thromboembolism, and in $4(80 \%)$ of 5 patients with bleeding complications (Fig 2). The mean INR before the occurrence of an event was within the target range in all 8 patients with thromboembolism, and in all 5 patients with bleeding complications. There was no correlation between the distribution of the INR and the occurrence of thromboembolic or bleeding events. None of these events occur

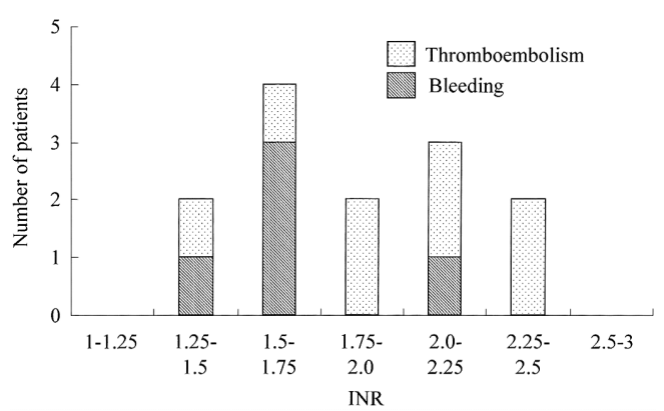

Fig 2. Occurrence of thromboembolic or bleeding events in each INR unit. INR, international normalized ratio.

in the early postoperative stage; they all developed more than 2 years after surgery.

In the univariate analysis of the various risk factors, those patients who had a tilting valve and an absence of antiplatelet therapy had an increased risk of thromboembolism (Table 1). In addition, multivariate logistic regression showed that a tilting valve and an absence of antiplatelet therapy were significant risk factors for thromboembolism (Table 2). However, there were no significant risk factors with respect to bleeding complications.

\section{Discussion}

Patients with mechanical heart valve prostheses need to receive life-long anticoagulation because of the high thromboembolic potential. However, the optimal anticoagulant intensity in patients with mechanical valves is still a matter of debate and several guidelines have been published. The American College of Chest Physicians in 1988 recom- 
mended a target INR of 3.0-4.5, whereas The American Heart Association in 1994 advocated a less intensive anticoagulation regimen with INR values between 2.5 and 3.5 . In 2001, the overall incidence of major hemorrhagic complications was still between 1.2 and 5.6 per 100 patient-years, and the rate of occurrence of thromboembolic events was between 0.4 and 6.5 per 100 patient-years? Recently, low rates of thromboembolism were achieved with low-dose warfarin treatment (a target INR of 2.0-2.5) combined with antiplatelet therapy?

Asians seem to be less vulnerable to thrombotic diseases than Caucasians. The incidence of thromboembolism is low in Japan, despite the less intensive regimen;2,3,8 however, guidelines for the optimal therapeutic range do not exist in Japan. Kitamura et al recommend an optimum range for the INR between 1.2 and 3.0 in patients with a low risk of thromboembolism, and between 2.0 and 3.0 in high-risk patients? The use of INR measurements for monitoring started in 1995 at Tenri Hospital and we advocate a therapeutic range between 1.5 and 2.5 .

In the present study, the incidence of bleeding complications was quite low, and the rate of thromboembolism was also low, despite the mild anticoagulation regimen. The close correlation between the level of anticoagulation and the risk of thromboembolism or bleeding complications has been well reported, but we also found that bleeding or embolic complications occurred despite the majority of patients being within the INR range most of the time. Kudo et al reported that in their study the INR was within the range of 1.6 to 2.8 in $71 \%$ of patients with thromboembolism and in $47 \%$ of those with bleeding complications? There may not be a clear relationship between the intensity of anticoagulation and the risk of complications in Japanese patients, although it is important to control the intensity within the target range?

Therefore, we made an assessment of the other factors that may contribute to the occurrence of complications. Our univariate analysis showed that patients with a tilting valve or who did not receive antiplatelet therapy had an increased risk of thromboembolism, but there were no risk factors with respect to bleeding complications.

The European Working Group recommended a more intensive anticoagulation regimen for patients with firstgeneration mechanical valves than for those with secondgeneration mechanical valves $!^{10}$ The present study confirmed the apparent higher thromboembolic risk for patients with a tilting valve.

The position of the prosthesis also influences the thromboembolic risk; ${ }^{10}$ the risk of a major embolism approximately doubled ( 0.9 per 100 patient-years) in patients with a mechanical valve in the mitral position ${ }^{11}$ However, in the present study, having an aortic prosthesis did not affect the risk of thromboembolism in patients with a mitral prosthesis.

Some studies have reported that antiplatelet therapy in addition to warfarin reduces the risk of thromboembolism with no increase in the risk of major bleeding7,12,13 but other have not had the same result! ${ }^{14}$ The optimum therapy is still unknown, although our study also showed that warfarin plus antiplatelet therapy significantly reduced embolic events. There were no risk factors with respect to bleeding complications in this study, although there have been many reports, albeit with confusing results on the risk factors for bleeding in anticoagulated patients. Elderly patients have been reported as having a higher risk for hemorrhagic complications, ${ }^{1}, 15$ but Fihn et al failed to find such an association! 16 A large-scale prospective multicenter clinical trial is needed to fully clarify this issue.

In conclusion, a target INR range of 1.5-2.5 appears to be the optimal range of anticoagulant intensity and prevents thromboembolism or bleeding complications in Japanese patients with mitral mechanical valves. Thromboembolism may be reduced by additional antiplatelet therapy, and a tilting valve needs more intense anticoagulation.

\section{References}

1. Cannegieter SC, Rosendaal FR, Winten AR, van der Meer FJ, Vandenbroucke JP, Briet E. Optimal oral anticoagulant therapy in patients with mechanical heart valves. $N$ Engl J Med 1995; 333: 11 17.

2. Kitamura M, Koyanagi H, Kawada S, Hosoda Y, Kurosawa H, Takeuchi Y, et al. Optimum anticoagulation control after bileaflet mechanical valve replacement: A prospective multi-institutional study. Kyobu Geka 1999; 52: 1001-1004.

3. Kudo T, Kawase M, Kawada S, Kurosawa H, Koyanagi H, Takeuchi Y, et al. Anticoagulation after valve replacement: A multicenter retrospective study. Artif Organs 1999; 23: 199-203.

4. Hirsh J, Poller L, Deykin D, Levine M, Dalen JE. Optimal therapeutic range for oral anticoagulants. Chest $1989 ; \mathbf{9 5}$ (Suppl 2): 5S-11S.

5. Hirsh J, Anand SS, Halperin JL, Fuster V. AHA Scientific Statement: Guide to anticoagulant therapy: heparin: A statement for healthcare professionals from the American Heart Association. Arterioscler Thromb Vasc Biol 2001; 21: E9-9.

6. Levine MN, Raskob G, Landefeld S, Kearon C. Hemorrhagic complications of anticoagulant treatment. Chest 2001; 119: 108S-121S.

7. Kudicky D, Essop MR, Wisenbaugh T, Skoularigis J, Essop AR, Dullabh A, et al. Frequency of prosthetic valve-related complications with very low level warfarin anticoagulation combined with dipyridamole after valve replacement using St Jude Medical prostheses. Am J Cardiol 1994; 74: 1137-1141.

8. Kimura M, Wasaki Y, Ogawa H, Nakatsuka M, Wakeyama T, Iwami $\mathrm{T}$, et al. Effect of low-intensity warfarin therapy on left atrial thrombus resolution in patients with nonvalvular atrial fibrillation. Jpn Circ J 2001; 65: 271-274.

9. Nozawa T, Asanoi H, Inoue H. Instability of anticoagulation intensity contributes to occurrence of ischemic stroke in patients with non-rheumatic atrial fibrillation. Jpn Circ J 2001; 65: 404-408.

10. Gohlke-Barwolf C, Acar J, Oakley C, Butchart E, Burckhart D, Bodnar E, et al. Guidelines for prevention of thromboembolic events in valvular heart disease: Study Group of the Working Group on Valvular Heart Disease of the European Society of Cardiology. Eur Heart J 1995; 16: 1320 -1330.

11. Cannegieter SC, Rosendaal FR, Briet E. Thromboembolic and bleeding complications in patients with mechanical heart valve prostheses. Circulation 1994; 89: 635-641.

12. Meschengieser SS, Fondevila CG, Frontroth J, Santarelli MT, Lazzari MA. Low-intensity oral anticoagulation plus low-dose aspirin versus high-intensity oral anticoagulation alone: A randomized trial in patients with mechanical prosthetic heart valves. J Thorac Cardiovasc Surg 1997; 113: 910-916.

13. Hayashi J, Nakazawa S, Oguma F, Miyamura H, Eguchi S. Combined warfarin and antiplatelet therapy after St Jude Medical valve replacement for mitral valve disease. J Am Coll Cardiol 1994; 23: 672-677.

14. Steele P, Rainwater J, Vogel R. Platelet suppressant therapy in patients with prosthetic cardiac valves: Relationship of clinical effectiveness to alteration of platelet survival time. Circulation 1979; 60: 910-913.

15. Palareti G, Leali N, Coccheri S, Poggi M, Manotti C, D'Angelo A, et al. Bleeding complications of oral anticoagulant treatment: An inception-cohort, prospective collaborative study (ISCOAT): Italian Study on Complications of Oral Anticoagulant Therapy. Lancet 1996; 348: 423-428.

16. Fihn SD, Callahan CM, Martin DC, McDonell MB, Henikoff JG, White RH. The risk for and severity of bleeding complications in elderly patients treated with warfarin: The National Consortium of Anticoagulation Clinics. Ann Intern Med 1996; 124: 970-979. 